Sharif University of Technology
Scientia Iranica
SCIENTIA
I RAN ICA
http://scientiairanica.sharif.edu

\title{
Performance evaluation of RC beam-column joints with different bonding interfaces
}

\author{
W. Jung ${ }^{\mathrm{a}}$, J. Kim ${ }^{\mathrm{b}}$, and M. Kwon ${ }^{\mathrm{c}, *}$ \\ a. Department of Civil Engineering, Gangneung-Wonju National University, Gangneung, 25457, South Korea. \\ b. Department of Civil Engineering, University of Texas at Arlington, Arlington, TX 76019, USA. \\ c. Department of Civil Engineering, ERI, Gyeongsang National University, Jinju, 52828, South Korea.
}

Received 24 January 2015; received in revised form 22 February 2016; accepted 1 October 2016

\author{
KEYWORDS \\ $\mathrm{RC}$ beam-column \\ joint; \\ Non-linear analysis; \\ Un-bonded rebar; \\ Seismic performance.
}

\begin{abstract}
Reinforced Concrete (RC) structures located on ocean coasts are damaged by salt water, leading to concrete deterioration. Due to this deterioration of the concrete, the metal rebar inside starts to corrode, because there is no longer concrete around it to prevent exposure to the outside environment. Such corrosion causes serious degradation of the cohesion between the steel and the concrete, and the performance capacity of the bonding between concrete and rebar. In this study, the performance of RC beam-column joints was evaluated. The interface between concrete and reinforcing bars in the $\mathrm{RC}$ beam-column joint specimens was partially un-bonded to simulate corrosion. The mechanical behavior and energy dissipation capacity of un-bonded RC beam-column joints were evaluated by experiment. Numerical studies were also performed with the help of finite element methods. Results from the experimental tests and numerical studies of RC beam-column joints at bonded and un-bonded interfaces between concrete and reinforcing bars are compared and discussed in terms of energy dissipation capacity, strength, and crack distribution.
\end{abstract}

(C) 2018 Sharif University of Technology. All rights reserved.

\section{Introduction}

Several earthquakes have occurred recently near the seashore of Japan that caused devastating damage to nuclear power plants. Consequently, the amount of radiation leaked to the Fukushima region has been substantial. It has also been observed that many secondary earthquakes usually follow major seismic events. With this in mind, much interest has been focused on the strengthening of existing structures to reduce future seismic damage in Korea, which is located close to Japan.

\footnotetext{
*. Corresponding author. Tel.: +82 55 r72 1796;

Fax: +82 55 r7q2 1799

E-mail addresses: woojung@gwnu.ac.kr (W. Jung); jskim0330@gmail.com (J.Kim); kwonm@gnu.ac.kr (M. Kwon)
}

doi: $10.24200 /$ sci. 2017.4175
Nuclear Power Plants (NPPs) must be located near water sources (e.g., the seaside) because they require substantial amounts of cooling. For that reason, in the case of Japan, tsunamis, a secondary effect of earthquakes, can damage NPP structures, which can remind others of the dangers of nuclear energy, making it a global issue. Such earthquakes and tsunamis put the structures made of reinforced concrete at a great risk. Reinforced concrete structures exposed to salt water for a long time can deteriorate, especially if they are older structures. Due to this deterioration, the alkali components in the concrete are neutralized. This means that the concrete has lost its ability to prevent corrosion and when the deterioration progresses to the concrete surrounding the rebar, the rebar starts to corrode. Such corrosion seriously degrades the cohesion between the steel and the concrete, thereby compromising the safety of the structure. In particular, the beam-column joints of 
reinforced concrete play important roles in the safety of reinforced concrete structures.

The first research conducted on $\mathrm{RC}$ beam-column joints focused on the settlement of the main bar of a beam and the energy loss due to shear resistance and reinforcement of a joint [1]. Since then, many researchers have carried out studies on this topic, including those dealing with the effects of transverse and longitudinal rebar, the validity of the confinement and cover thickness $[2,3]$, and the effect of anchorage length on the hysteretic behavior of joints due to the reduction in bonding strength. Recently, research has been conducted on a variety of issues related to evaluation of the seismic performance of joints. Most of them are experimental studies on the performance capacity of beam-column joints. Clyde et al. [4] and Pantelides et al. [5] performed cyclic tests on exterior beam-column joints with an axial load. In their research, the joints were designed in such a way as to have joint shear failures before the yielding of the beam bars. The longitudinal and transverse reinforcement in the beam, and the column transverse reinforcement, were increased to prevent early degradation of the beam and column, forcing a shear mode of failure in the joint. Murty et al. [6] performed cyclic tests with various anchorages of beam bars and different types of joint reinforcement. Hwang et al. [7] performed tests on exterior joints having different reinforcement details. Their studies were aimed at obtaining elementary data on the RC beam-column joints of reinforced concrete subjected to loss of cohesion between the steel and concrete due to serious corrosion.

Meanwhile, researchers have attempted to model the behavior of $\mathrm{RC}$ beam-column joints using various approaches that include lumped plasticity models [8], multi-spring models [9-13], and empirical models [1416] based on experimental results [17]. Lowes et al. [18] attempted to model the interface-shear based on experimental data from which they predicted the stiff elastic response of the interface-shear. The experimental data for validation included specimens with a minimal amount of transverse reinforcement in the panel zone, which is consistent with the intended use of the model. Because joints without transverse reinforcement were excluded from the study, the model is not suitable for analysis of joints with transverse reinforcement.

Altoontash [19] simplified the model proposed by Lowes and Altoontash [18] by introducing four zero-length rotational springs located at beam-column joint interfaces. The rotational springs simulated the member-end rotations due to bond-slip behavior and the panel zone component with a rotational spring simulated the shear deformation of the joint. The development length was assumed to be adequate to prevent complete pullout.

Though many experimental and analytical studies on $\mathrm{RC}$ beam-column joints have been conducted thus far, they rest upon the assumption that the rebar and concrete are perfectly bonded, which is not realistic. As a result, current performance analysis does not take severe steel corrosion and concrete carbonation of the RC members into account. This study was focused on evaluation of the performance of $\mathrm{RC}$ beamcolumn joints with partially un-bonded reinforcement in the beam area. Rubber tubes were installed over the rebar to simulate the loss of adhesive capacity. Both the cyclic behavior and seismic performance of the RC beam-column joints were evaluated under lateral cyclic loading, considering the characteristics of rebar-concrete bonded and un-bonded behaviors. To simulate un-bonded behavior of the reinforcement bar indirectly using finite element analysis, the yield strength and elastic modulus of the rebar were adjusted based on the experimental results and fiber section analysis.

\section{Experimental program}

\subsection{Test specimens}

Experimental tests were done to evaluate the seismic performance of beam-column joints that had lost bond strength between the concrete and reinforcing bars due to the corrosion of the bars. The RC beam-column joints of the test specimens were scaled down to onethird of a standard reinforced concrete frame. The specimens were designed and constructed according to the building code requirements proposed by the ACI Committee (318-95) [20]. The cross-sectional area of the column and the beam was $200 \times 200 \mathrm{~mm}$ as shown in Figure 1. The anchorage type and length of the tensile steel are depicted in Figure 1. The anchorage types were used as one of the parameters in this study. The anchorage type affects the destruction of the beamcolumn joints [21]. As shown in Figure 2(b) and (d), thin rubber tubes were installed over the main rebar to simulate un-bonding between the concrete and the rebar. Four specimens were put into two groups, one having L-type rebar and the other having U-type rebar. Each group had two types of bonded and un-bonded interfaces between the rebar and concrete (Table 1).

Table 1. Test specimens.

\begin{tabular}{ccl}
\hline Specimen & $\begin{array}{c}\text { Type of } \\
\text { joint rebar }\end{array}$ & $\begin{array}{c}\text { Type of } \\
\text { anchorage } \\
\text { interface }\end{array}$ \\
\hline LBD & L-Type & Bonded \\
LUD & L-Type & Un-bonded \\
UBD & U-Type & Bonded \\
UUD & U-Type & Un-bonded \\
\hline
\end{tabular}




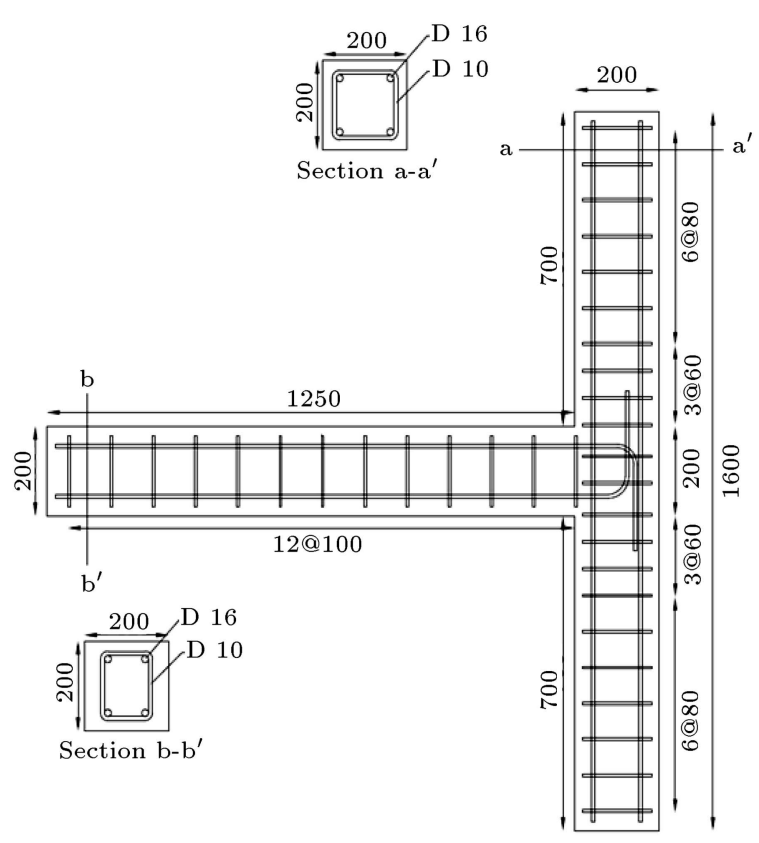

(a) L-type

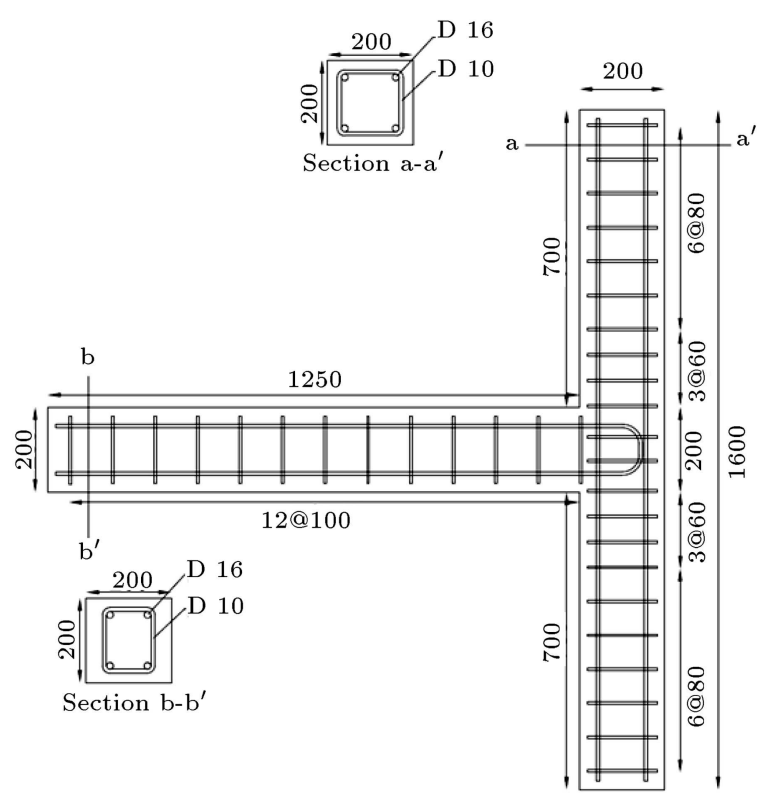

(b) U-type

Figure 1. Dimensions of beam-column joint.

\subsection{Material properties}

Deformed rebar with yield strength of $400 \mathrm{MPa}$ was used. D16 (Diameter $16 \mathrm{~mm}$ ) was used as the main rebar while D10 was used as the hoop stirrup. In order to measure the properties of the rebar, three specimens were tested according to ASTM-A370. The results are shown in Table 2.

The concrete was designed to have compressive strength of $21 \mathrm{MPa}$, with $25 \mathrm{~mm}$ maximum aggregate size and $120 \mathrm{~mm}$ slump. To determine the compressive strength of the concrete, three specimens were tested on

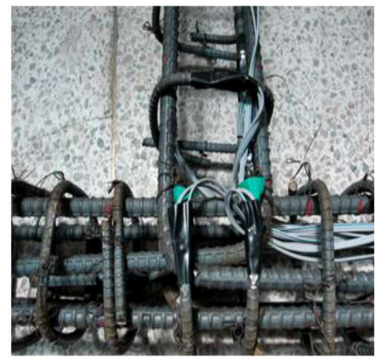

(a) LBD

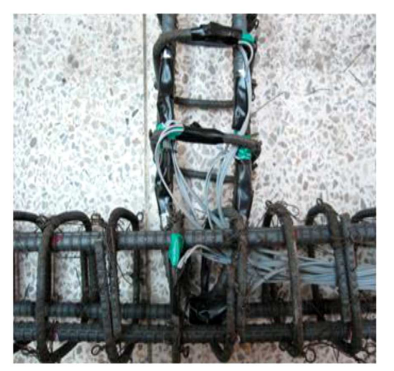

(c) UBD

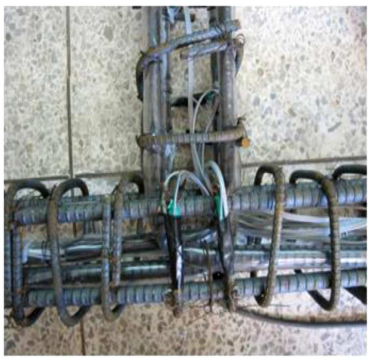

(b) LUD

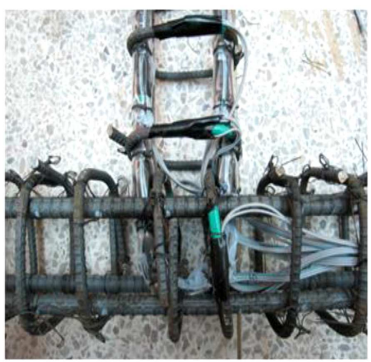

(d) UUD
Figure 2. State of the joint rebar.

Table 2. Properties of the rebar.

\begin{tabular}{cccc}
\hline Type & $\begin{array}{c}\text { Yield } \\
\text { tensile } \\
\text { strength } \\
\left(\boldsymbol{f}_{\boldsymbol{y}}, \mathbf{M P a}\right)\end{array}$ & $\begin{array}{c}\text { Ultimate } \\
\text { tensile } \\
\text { strength } \\
\left(\boldsymbol{f}_{\boldsymbol{u}}, \mathbf{M P a}\right)\end{array}$ & $\begin{array}{c}\text { Elastic } \\
\text { modulus } \\
(\mathbf{M P a})\end{array}$ \\
\hline D10 & 419 & 561 & $2.26 \times 10^{5}$ \\
D16 & 438 & 598 & $1.97 \times 10^{5}$ \\
\hline
\end{tabular}

the same day of the experiments according to ASTMC39. The test results for the compressive strength of the concrete are summarized in Table 3.

\subsection{Test setup}

A steel-frame was fabricated as shown in Figure 3 for testing the beam-column joint. The test specimen was set up with various experimental data acquisition devices, as shown in Figures 3 and 4. Due to constraints in the experimental environment, the column was set up to horizontal direction and axial force was exerted on the end of the column. At the initial stages, the column of the beam-column joint was set up horizontally with respect to the basic frame. Then, a reaction frame was set up on one side and an oil jack with a capacity of $200 \mathrm{kN}$ was placed on the other side later, in order to apply a constant axial load. A constant axial load of $84 \mathrm{kN}$ (corresponding to

Table 3. Properties of the concrete.

\begin{tabular}{|c|c|c|}
\hline \multirow{2}{*}{$\begin{array}{c}\text { Design } \\
\text { strength } \\
(\mathrm{MPa})\end{array}$} & \multicolumn{2}{|c|}{ Test results } \\
\hline & $\begin{array}{c}\text { Compressive } \\
\text { strength } \\
(\mathrm{MPa})\end{array}$ & $\begin{array}{c}\text { Elastic } \\
\text { modulus } \\
(\mathrm{MPa})\end{array}$ \\
\hline 21 & 23.8 & $2.65 \times 10^{4}$ \\
\hline
\end{tabular}




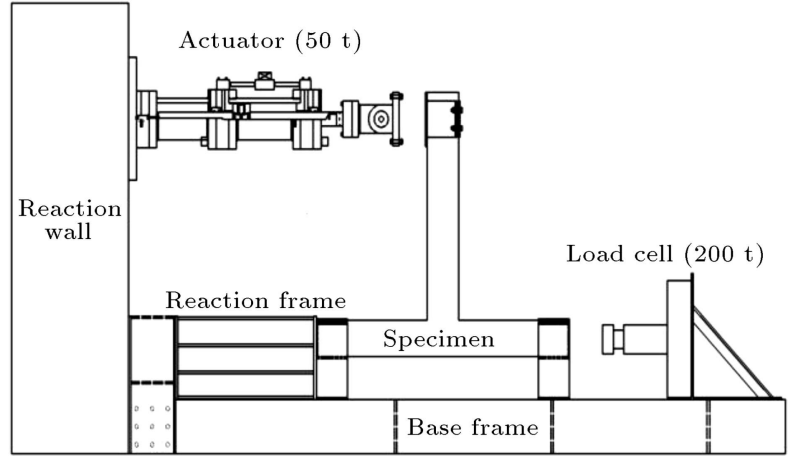

Figure 3. Test setup of RC beam-column joint.

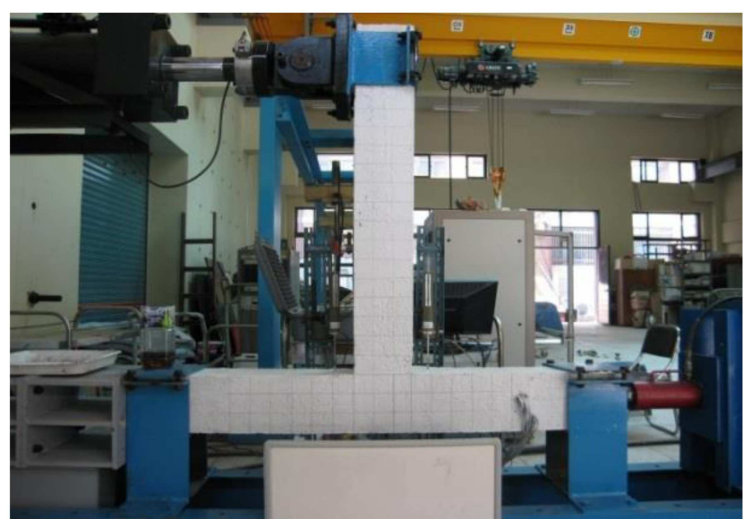

Figure 4. Photo of RC beam-column joint test setup.

approximately $\left.0.1 \times A_{g} \times f_{c k}\right)$ was generated through oil jacks.

An actuator of $500-\mathrm{kN}$ capacity was installed in the reaction wall to perform a cycle loading test on the beam-column joint. A steel cap was used to fix the actuator and the end of the specimen beam. The actuator applied displacement loads following a loading history created using a displacement ductility factor. This was derived based on the determined yield displacement obtained using a monotonic test of specimen STD.

The loading history curve is plotted as the displacement ductility factor in Figure 5.

\subsection{Experimental results and discussion \\ 2.4.1. Distribution of cracks}

The crack pattern in each test specimen, with respect to the displacement ductility factor, is shown in Figure 6 . For the specimen LBD, flexural cracks occurred at the interface of the beam-column joint when the displacement ductility factor was $\mu=1$ (2nd cycle). Shear cracks occurred at the interface of the beamcolumn joint starting with a displacement ductility factor of $\mu=2$ (4th cycle) and continued until $\mu=4$ (8th cycle). The progression of shear cracks near the joint slowed down, while the range of flexural cracks increased at the interface of the joint until reaching the final loading stage $(\mu=6,10$ th cycle $)$. For

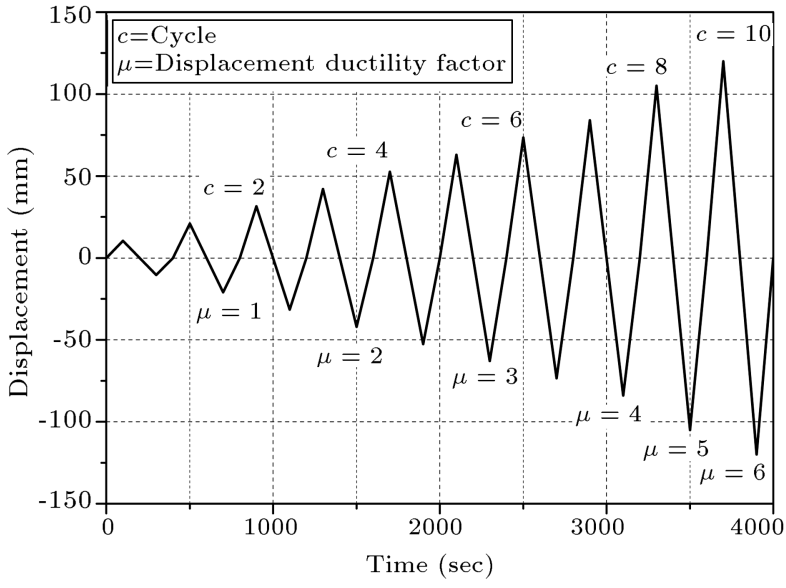

Figure 5. Loading protocol of RC beam-column joint.

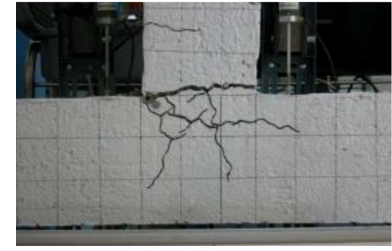

(a) LBD

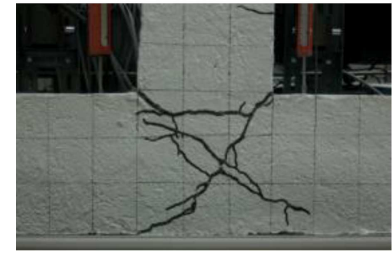

(c) UBD

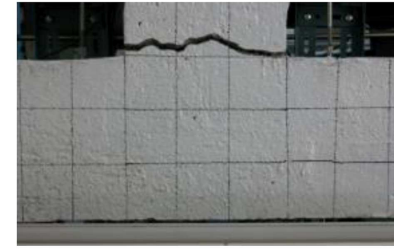

(b) LUD

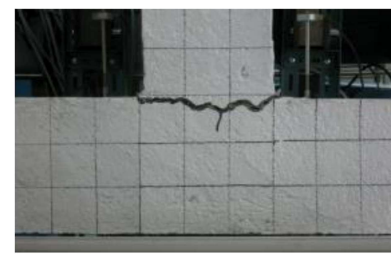

(d) UUD
Figure 6. Crack distribution of RC joint at final loading.

the specimen LUD, flexural cracks first developed at the interface of the beam and column starting at the displacement ductility factor of $\mu=1$ (2nd cycle). However, cracks did not propagate to the joint when the displacement ductility factor ranged from $\mu=2$ (4th cycle) to $\mu=6$ (10th cycle), but the width of the flexural cracks at the boundary surfaces of the beamcolumn grew gradually.

For the specimen UBD, flexural cracks started to be developed at the interface of the beam-column joints when the displacement ductility factor was $\mu=1$ (2nd cycle). Shear cracks at the interface of the beamcolumn spread to the joint at $\mu=2$ (4th cycle). After that, shear cracks propagated into the column at the end of the test and the width of the flexural cracks increased. For the specimen UUD, cracks in the Utype un-bonded specimen did not spread to the joint until the final load stage, but wide flexural cracks were opened at the interface.

Both shear and flexural cracks developed in the bonded specimens, while only flexural cracks developed in the un-bonded ones. This was mainly because the 
transfer of stress between the concrete and rebar did not take place in the un-bonded joints.

\subsubsection{Load-displacement relation}

Figure 7 shows the relation between the lateral load and displacement of beam-column joints. For the specimen LBD, maximum load was $22.2 \mathrm{kN}$ and displacement at maximum load was $58.3 \mathrm{~mm}$. This indicates ductile behavior. When the displacement exceeded $105 \mathrm{~mm}$, the lateral load decreased steadily due to yielding of the longitudinal reinforcement. For the specimen LUD, the maximum load was $12.6 \mathrm{kN}$ and displacement at maximum load was $101.0 \mathrm{~mm}$. The load increased until the displacement reached $39.8 \mathrm{~mm}$. The initial yielding of the rebar occurred at $8.8 \mathrm{kN}$ of lateral load. For the specimen UBD, the maximum load was $23.0 \mathrm{kN}$ and the corresponding displacement was $61.4 \mathrm{~mm}$. After the peak load, the strength decreased and the number of shear cracks increased. For the specimen UUD, the maximum load was $15.5 \mathrm{kN}$ and the corresponding displacement was $115.6 \mathrm{~mm}$. The initial yield of the rebar occurred at $11.3 \mathrm{kN}$. The strength decreased after the peak load.

In order to compare the experimental results obtained with each specimen, LBD and UBD were set as reference specimens. Comparisons of these with other specimens (such as LUD and UUD) with

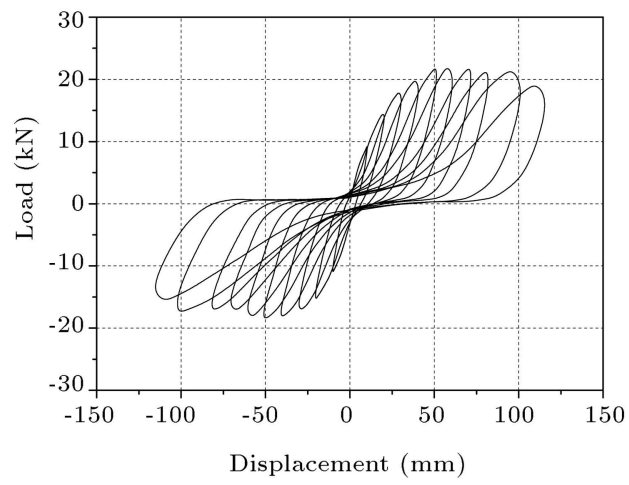

(a) LBD

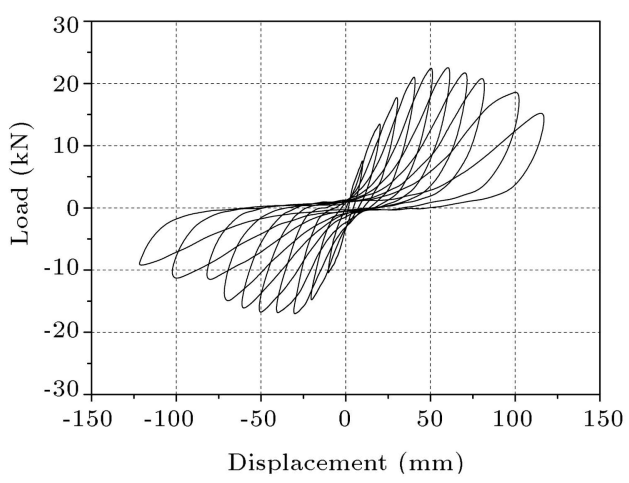

(c) UBD respect to strength in the forward direction $(+)$ and displacement are summarized in Table 4.

The maximum load for specimen LUD decreased to $56.7 \%$ of that for LBD, while the displacement at maximum strength increased by about $173.3 \%$. The maximum load for specimen UUD decreased to $67.1 \%$ of that for UBD, while the displacement at maximum strength increased by about $188.3 \%$.

The results of tests of the strength and displacement of the L- and U-type specimens indicate that the maximum strength of the un-bonded beam-column joint decreased, and that the displacement at peak strength increased due to slip that occurred in the joint. Moreover, U-type specimens exhibited less strength and greater deformation at the peak than the L-type specimens did.

\subsubsection{Strain of the beam in the plastic hinge region}

The strain of the rebar was measured with strain gauges installed in the rebar at the interface of the beam and column, where the flexural cracks were expected to occur. The data are presented in Figure 8, which shows the peak strain of the rebar in each cycle.

In the case of the specimen LBD, the peak strength reached the 3rd cycle in the loading history and the strain of the rebar at the interface was 0.002650. In the case of specimen LUD, although the applied load increased up to the 5th cycle, the strain

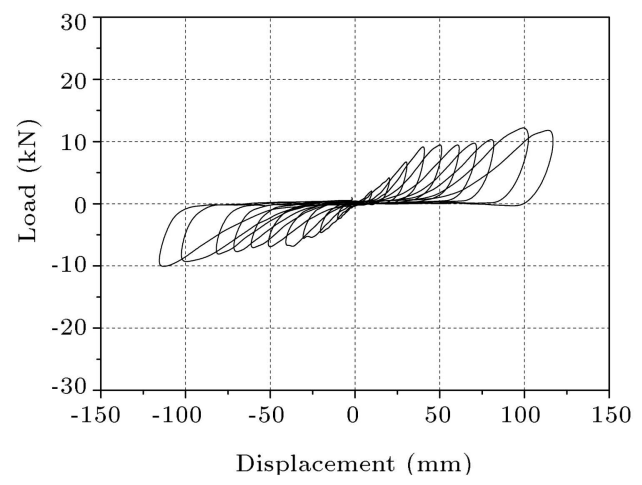

(b) LUD

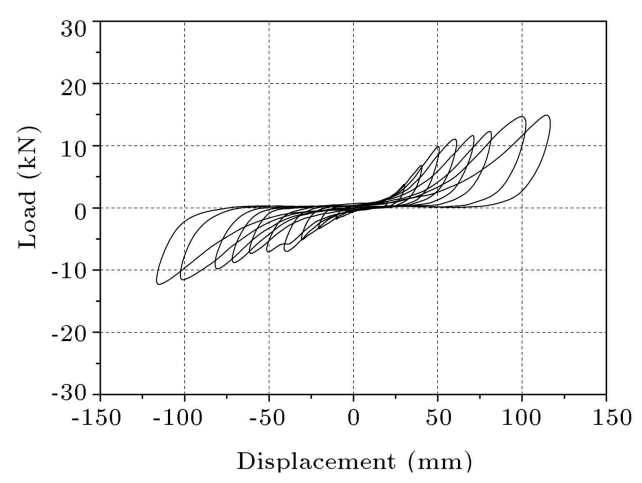

(d) UUD

Figure 7. Load-displacement relationship curve. 
Table 4. Summary of experimental results.

\begin{tabular}{|c|c|c|c|c|c|c|}
\hline \multirow{2}{*}{ Specimens } & \multirow{2}{*}{$\begin{array}{c}\text { Failure } \\
\text { type of } \\
\text { joint }\end{array}$} & \multicolumn{2}{|c|}{ Maximum strength } & \multicolumn{2}{|c|}{$\begin{array}{l}\text { Strains of the beam } \\
\text { in the hinge region }\end{array}$} & \multirow{2}{*}{$\begin{array}{c}\text { Total energy } \\
\text { dissipation } \\
\text { capacity } \\
(\text { kN.m) }\end{array}$} \\
\hline & & $\begin{array}{l}\text { Load } \\
(\mathrm{kN})\end{array}$ & $\begin{array}{l}\text { Displacement } \\
(\mathrm{mm})\end{array}$ & $\begin{array}{c}\text { Cycle } \\
\text { (peak) }\end{array}$ & Strain & \\
\hline LBD & Shear, flexural & 22.195 & 58.303 & 3rd & 0.00265 & 7.595 \\
\hline LUD & Flexural & 12.596 & 101.031 & 5 th & 0.000461 & 4.529 \\
\hline UBD & Shear, plastic & 23.027 & 61.379 & $3 \mathrm{rd}$ & 0.00166 & 6.905 \\
\hline UUD & Plastic & 15.458 & 115.586 & 5 th & 0.000367 & 5.556 \\
\hline
\end{tabular}

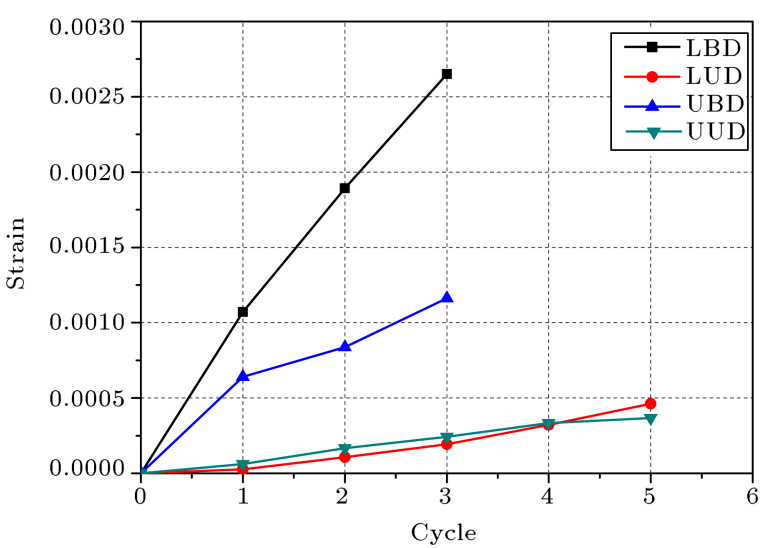

Figure 8. Strain of longitudinal rebar.

at peak strength was 0.000461 , which was smaller than that of specimen type LBD. The U-type bonded specimen, UBD, reached peak strength when the strain was measured as 0.001160 at the 3rd cycle in the loading protocol. In the case of the un-bonded specimen UUD, even though the applied load increased up to the 5th cycle, the strain at peak strength was measured as 0.000367 , which was lower than that of specimen type UBD. The strain of the rebar in the plastic hinge region of the specimens is summarized in Table 4.

In Table 4, the strain on the rebar of the bonded specimen increased greatly around the flexural cracks, even at earlier loading cycles. In contrast, the tensile stress of the rebar in the un-bonded specimen decreased due to the lack of bonding between the concrete and rebar. The strain of the un-bonded specimen, therefore, did not increase significantly even with increases in the load and displacement. Also, the initial strain in the U-type specimen was less than that in the Ltype specimen. Based on the analysis of strain at the yield point, the adhesive performance of the rebar and concrete seemed to be more effective in the L-type than in the U-type.

\subsubsection{Energy dissipation capacity}

Energy dissipation capacity is the energy absorbed by the structural members while they maintain their strength. The resistance to external forces by deforming of the structural members by cyclic load can be measured using the capacity of energy dissipation of the specimen.

Before deriving the energy dissipation capacity, a strength history curve against the displacement ductility factor for each of the specimens was drawn. Based on the curves shown in Figure 9, the energy dissipation capacity and the accumulated energy dissipation capacity are computed and presented in Figures 10 and 11.

The energy dissipation capacity of all the specimens increased in each cycle up to the displacement

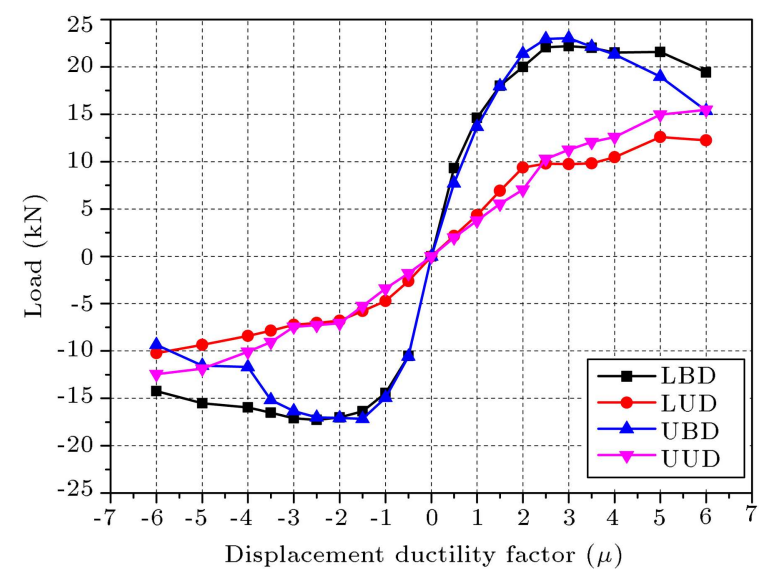

Figure 9. Strength history curve of the beam-column joints.

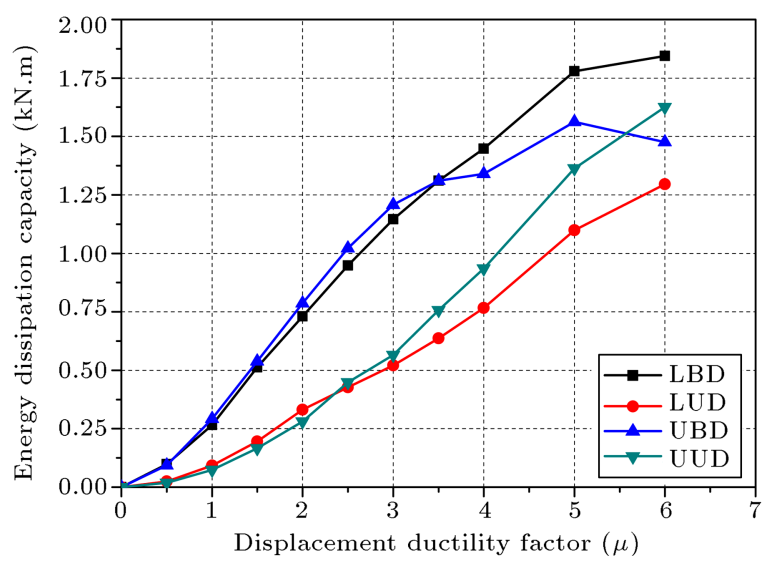

Figure 10. Energy dissipation capacity at displacement ductility factor. 


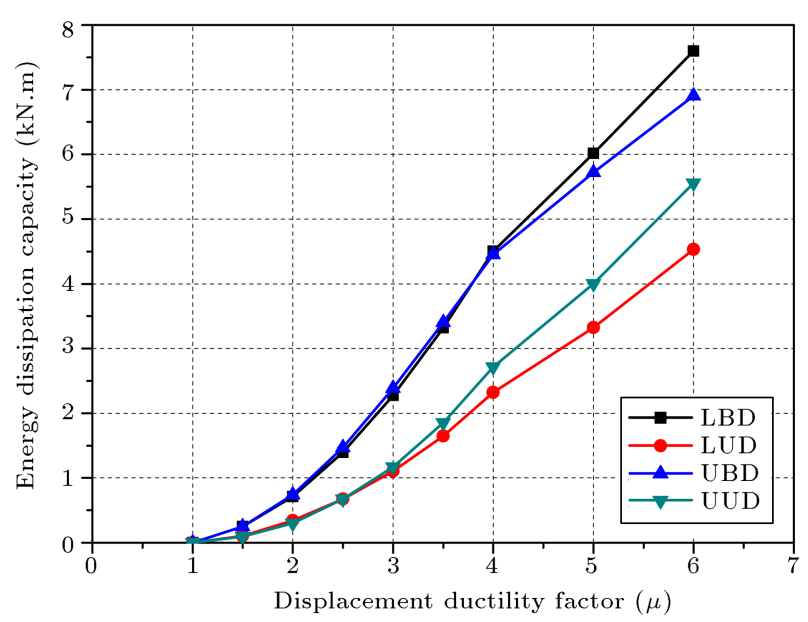

Figure 11. Accumulated energy dissipation capacity at displacement ductility factor.

ductility factor of $\mu=5$. In specimen UBD, however, the energy dissipation capacity decreased for the final displacement ductility factor. Specimen LBD accumulated $7.595 \mathrm{kN} . \mathrm{m}$ of energy dissipation until it reached the maximum displacement ductility factor, while the LUB specimen accumulated only $4.529 \mathrm{kN}$.m. The UBD specimen accumulated $6.905 \mathrm{kN}$.m of energy dissipation until it reached the maximum displacement ductility factor, while the UUD specimen accumulated $5.556 \mathrm{kN} . \mathrm{m}$. The energy dissipation capacities of the specimens are summarized in Table 4.

The bonded specimens showed greater strength and less yield displacement than the un-bonded specimens did. The energy dissipation capacities of the unbonded specimens were approximately $40 \%$ and $20 \%$ less for the L-type and U-type specimens, respectively, than for bonded specimens. This was caused by the decreased strength and increased deformation that occurred in the un-bonded specimens.

\section{Numerical study}

\subsection{Modeling of un-bonded states}

The bonded and un-bonded beam-column joints were analyzed using a finite element method to evaluate the test results. For the analysis, two different finite element models were proposed to consider the bonding characteristics between concrete and rebar. One model of an un-bonded specimen assumed that the stress of the concrete did not transfer to the rebar at the interface of the concrete and rebar. Such a model includes the slip of rebar during tension failure of an $\mathrm{RC}$ member, and therefore reduces the stress exerted on the rebar. The material properties of the rebar were derived with the assumption that the rebar elastic modulus did not affect the composite section because it was not bonded with the concrete. Therefore, the material properties of the rebar were estimated from the load-displacement relation of the experimental result with the un-bonded specimens.

Nonlinear fiber sections analysis was used to derive the properties of the un-bonded rebar in the RC members. Based on the fiber model, nonlinear fiber sections analysis considered the interaction between axial force and moment by decomposing the $\mathrm{RC}$ section into multiple layers.

Through the fiber sections analysis, the moment and curvature of the beam structure were calculated. The elastic modulus and strength of the un-bonded rebar were derived from the calculations. The material properties used for the numerical analysis are shown in Table 5.

\subsection{Numerical analysis}

\subsubsection{Numerical modeling}

The ABAQUS [22] program was used for numerical analysis. The load-displacement relationship and experimental results of the cracks of the specimens were compared. The specimen used in the experiment was modeled, as shown in Figure 12. The concrete was discretized as a 20-node solid element with reduced integration technique. Also, a damaged plasticity concrete model was used as the constitutive model of concrete [23]. The rebar was discretized as truss elements and embedded into the solid elements. The plasticity model was used as the constitutive law of the rebar. More detailed description of the numerical modeling is given elsewhere [24,25]. The concrete compression strength and elastic modulus from the material properties tests were applied to the properties of both the bonded and un-bonded specimens. The un-bonded rebar region $\left(l_{d}, 850 \mathrm{~mm}\right)$ is indicated in Figure 12.

The properties of Table 2 were applied to the bonded rebar, the properties of Table 3 were applied to concrete, and the properties of Table 5 were applied to un-bonded rebar in the analysis.

The displacement load was applied to the top part of the beam. The degree of freedom was fixed except in the axial direction to consider the boundary condition of the column under the experimental conditions. Hence, one side of the two-faced column was fixed, while the axial force of $84 \mathrm{kN}$ was applied on the other side.

\subsubsection{Numerical results}

The rebar stress and distribution of the cracks in the concrete are shown in Figures 13 and 14. For both bonded and un-bonded specimens, the rebar around the joint reached the yield stress first. The rebar stress on the axial columns was greater in the un-bonded specimen than in the bonded one, and both types of specimens showed flexural fractures.

As for the distribution of concrete cracks, Fig- 
Table 5. Un-bonded rebar properties based on section analysis.

\begin{tabular}{ccccc}
\hline & $\begin{array}{c}\text { Un-bonded } \\
\text { section } \\
\left(\boldsymbol{l}_{\boldsymbol{d}}\right)\end{array}$ & $\begin{array}{c}\text { Yield tensile } \\
\text { strength } \\
\left(\boldsymbol{f}_{\boldsymbol{y}}, \mathbf{M P a}\right)\end{array}$ & $\begin{array}{c}\text { Ultimate tensile } \\
\text { strength } \\
\left(\boldsymbol{f}_{\boldsymbol{u}}, \mathbf{M P a}\right)\end{array}$ & $\begin{array}{c}\text { Modulus } \\
(\mathbf{M P a})\end{array}$ \\
\hline \multirow{2}{*}{ D16 } & L-Type & 180 & 250 & $3.70 \times 10^{5}$ \\
& U-Type & 260 & 380 & $5.60 \times 10^{5}$ \\
\hline
\end{tabular}

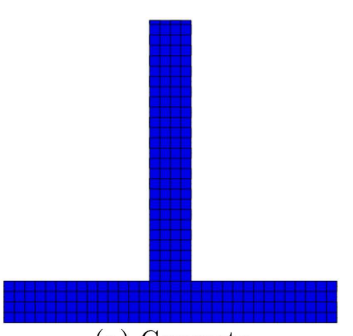

(a) Concrete

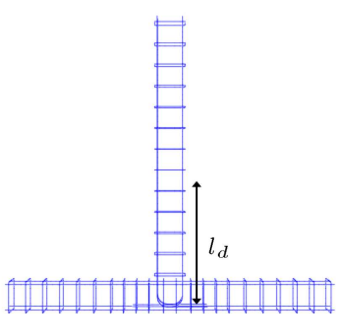

(b) L-type reinforcement

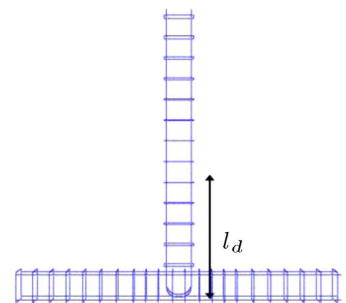

(c) U-type reinforcement

Figure 12. Finite element modeling.

ure 14 shows that both flexural and shear cracks were distributed in the region of the beam-column joint for the bonded specimens, while a relatively larger number of flexural cracks was found there in the un-bonded specimens. The distribution of concrete cracks of each of the specimens was similar in the cycle loading test. Also, larger shear cracks were seen in the bonded U-type specimens than in the Ltype specimens. This shows that the L-type specimen delayed the development of shear cracks more than the U-type specimens did.

Figure 15 compares the numerical results by ABAQUS and the experimental results for the relation between the load and displacement. The numerical and experimental load-displacement relations of the specimens were similar. Comparison of the numerical results and experimental results is summarized in Table 6 . The numerical results for the bonded specimens (at the

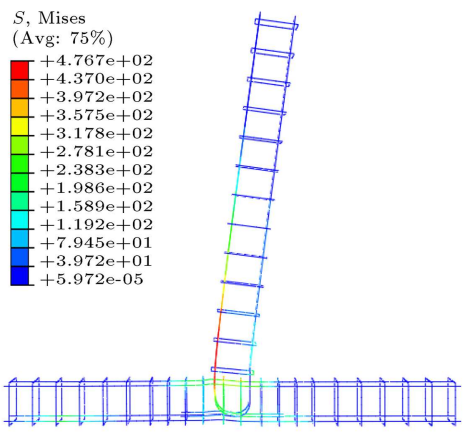

(a) LBD

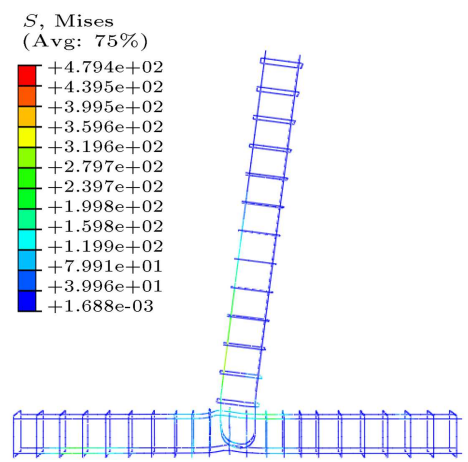

(c) UBD

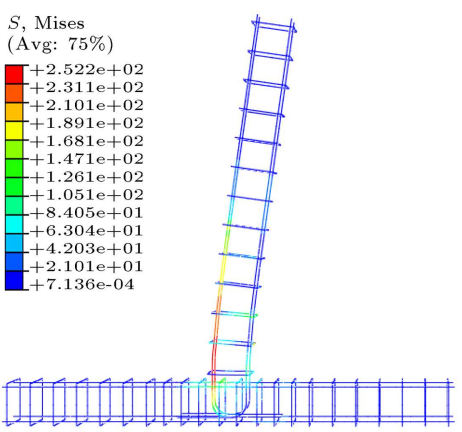

(b) LUD

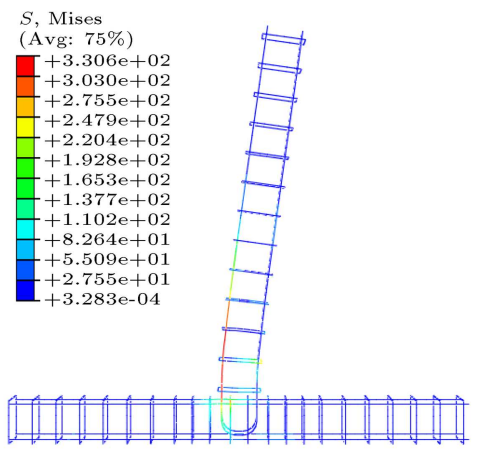

(d) UUD

Figure 13. Rebar stress results. 


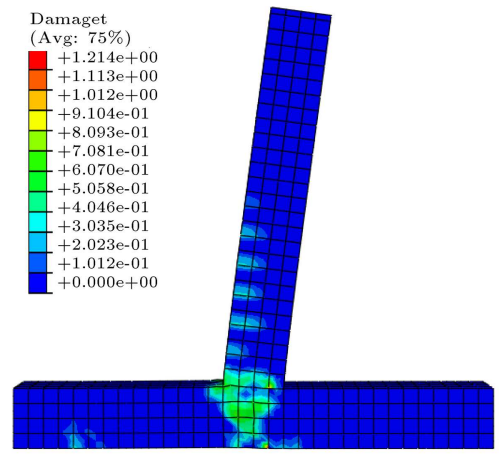

(a) Bonded joint of hook type

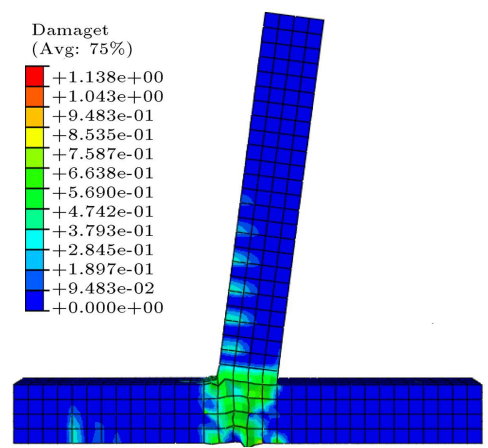

(c) Bonded joint of U-type

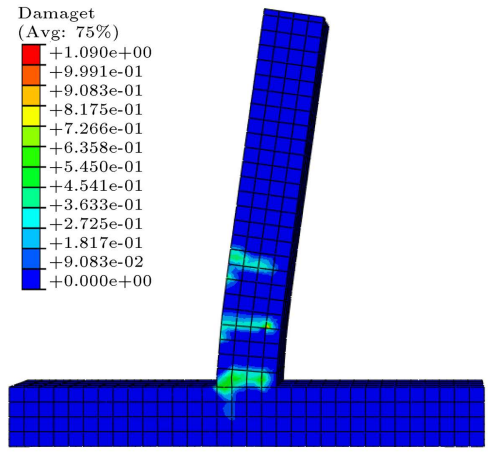

(b) Un-bonded joint of hook type

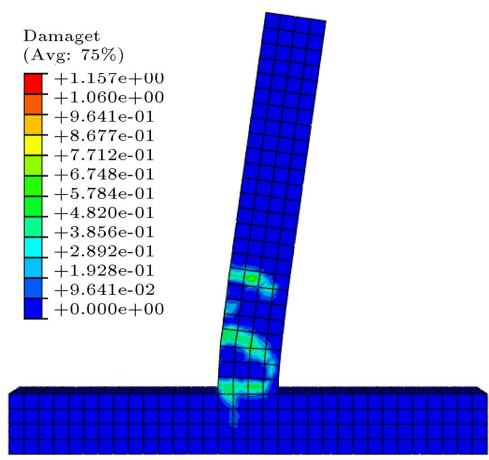

(d) Un-bonded joint of U-type

Figure 14. Concrete crack distribution results.

beam-column joint) were that flexural failures occurred first, followed by shear failures, whereas only flexural failures occurred for the un-bonded specimens. Shear cracks for the U-type were wider than for the L-type.
Due to its shape, the L-type seemed to slow down the progress of shear cracks. The failure patterns seen in both the numerical and experiments were very similar in both U-type and L-type specimens.

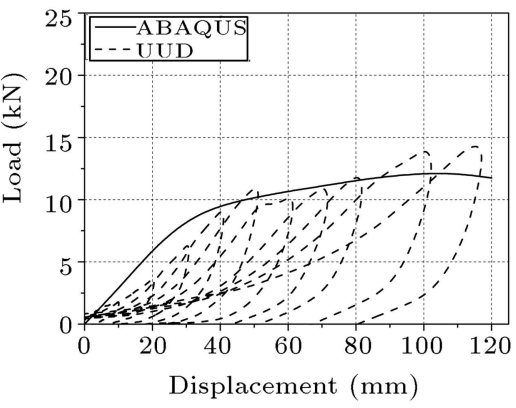

(b) LUD

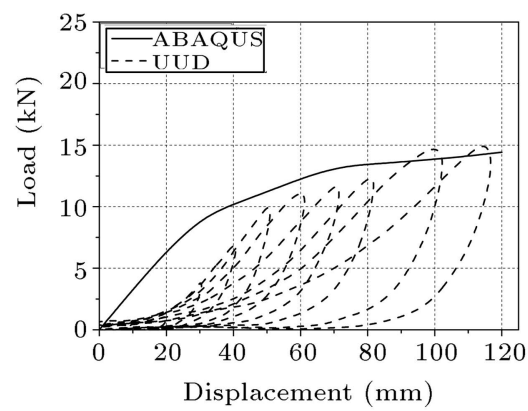

(d) UUD

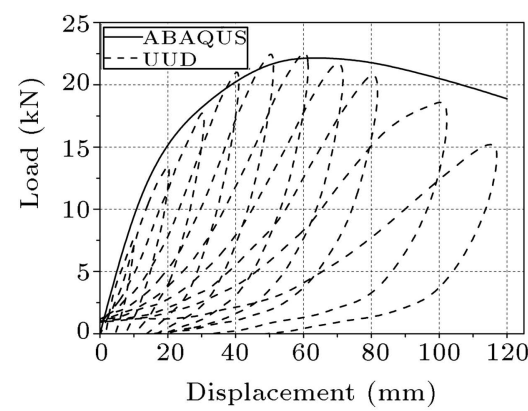

(c) UBD

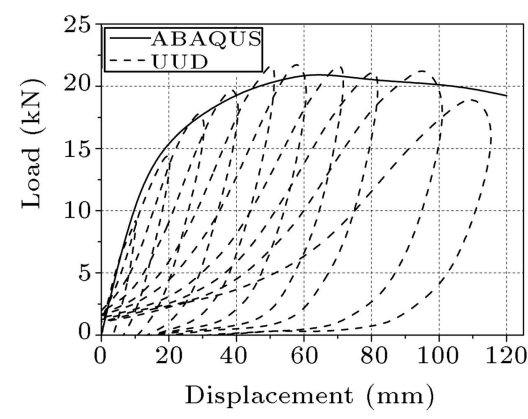

(a) LBD

Figure 15. Comparison of experimental and analytical results. 
Table 6. Summary of analytical results.

\begin{tabular}{clccc}
\hline \multirow{2}{*}{ Specimens } & \multirow{2}{*}{$\begin{array}{c}\text { Failure type } \\
\text { of joint }\end{array}$} & \multicolumn{2}{c}{ Maximum strength } & Final \\
\cline { 3 - 4 } & Load (kN) & Displacement $\mathbf{( m m})$ & state \\
\hline LBD & Shear, flexural & 21.050 & 63 & Yield \\
LUD & Flexural & 12.284 & 105 & Yield \\
UBD & Shear, flexural & 22.224 & 63 & Yield \\
UUD & Flexural & 14.431 & 120 & Not yield \\
\hline
\end{tabular}

Even the overall behavior of the joints was well predicted by the numerical analysis, but the initial stage of the un-bonded specimen showed some discrepancy in numerical results.

The average stress on the rebar where shear cracks occurred was greater in the bonded specimen than in the un-bonded specimen. This could be due to the activity of the beam rebar in the un-bonded specimen, which reduces the strength transferred to the joint, stopping the progress of shear cracks.

\section{Conclusions}

In this research, the mechanical behavior and energy dissipation capacity of bonded and un-bonded beamcolumn joints were evaluated. Both experimental and numerical studies were conducted. The conclusions derived from this study are as follows:

1. The experiment results show that when L-type and U-type beam-column joints were un-bonded, the maximum strength decreased while the yield displacement increased. The strength decreased due to activity between the rebar and concrete caused by non-bonding, but the ductility increased. The bonded specimens showed both flexural and shear cracks, but the un-bonded specimens showed flexural cracks only;

2. The energy dissipation decreased by $60 \%$ in the L-type and by $80 \%$ in the U-type when results from un-bonded and bonded joints were compared. Contrary to the increase in ductility, the strength decreased, which resulted in a lower energy dissipation capacity in the case of un-bonded joints. From the accumulated energy dissipation from the cycle loading test results, it was found that the yield displacement increased due to the un-bonded rebar, but the energy dissipation did not increase due to a significant reduction in strength;

3. The numerical analysis result for the un-bonded beam-column joint showed a difference in initial stiffness compared to the experimental results. However, as the displacement increased, the loading hysteresis, maximum strength, and yield displacement were very well predicted.

\section{Acknowledgement}

This work was supported by the National Research Foundation of Korea (NRF) grant funded by the Korea government (MEST) (No. 2012-0008762).

\section{References}

1. Hanson, N.W. and Conner, H.W. "Seismic resistance of reinforced concrete beam-column joint", ACI Structural Journal, 7, pp. 533-560 (1967).

2. Megget, L.M. and Park, R. "Reinforced concrete exterior beam-column joints under seismic loading", New Zealand Engineering, 26, pp. 341-353 (1971).

3. Uzumeri, S.M. and Seckin, M. "Behaviour of reinforced concrete beam-column joints subjected to slow load reversals", Report No. 74-05, Department of Civil Engineering, University of Toronto, Toronto, Ontario, Canada (1974).

4. Clyde, C., Pantelides, C.P. and Reaveley, L.D. "Performance-based evaluation of exterior reinforced concrete building joints for seismic excitation", Report PEER 2000/05, Pacific Earthquake Engineering Research Center (2000).

5. Pantelides, C.P., Hansen, J., Nadauld, J. and Reaveley, L.D. "Assessment of reinforced concrete building exterior joints with substandard details", Report no. PEER 2002/18. Pacific Earthquake Engineering Research Center (2002).

6. Murty, C.V.R., Rai, D., Bajpai, K.K. and Jain, S.K. "Effectiveness of reinforcement details in exterior reinforced concrete beam-column joints for earthquake resistance", ACI Structural Journal, 100(2), pp. 149156 (2003).

7. Hwang, S.H., Lee, H.J., Liao, T.F., Wang, K.C. and Tsai, H.H. "Role of hoops on shear strength of reinforced concrete beam-column joints", ACI Structural Journal, $102(3)$, pp. 445-453 (2005).

8. Otani, S. "Inelastic analysis of RC frame structures", Journal of the Structural Division, ASCE, 100(ST7), pp. 1433-1449 (1974).

9. Filippou, F., Popov, C., Egor, P. and Bertero, Vitelmo V., Effects of Bond Deterioration on Hysteretic Behavior of Reinforced Concrete Joints, Earthquake Engineering Research Center, University of California, Berkeley (1983). 
10. Filippou, F.C. and Issa, A. "Nonlinear analysis of reinforced concrete frames under cyclic load reversals", EERC report UCB/EERC-88/12 (1988).

11. El-Metwally, S.E. and Chen, W.F. "Moment-rotation modeling of reinforced concrete beam-column connections", ACI Structural Journal, 85(4), pp. 384-94 (1988).

12. Alath, S. and Kunnath, S.K. "Modeling inelastic shear deformations in RC beam-column joints", Engineering Mechanics Proceedings of 10th Conference, May 21-24, University of Colorado at Boulder, Boulder, Colorado, 2, New York, ASCE, pp. 822-5 (1995).

13. Biddah, A. and Ghobarah, A. "Modelling of shear deformation and bond slip in reinforced concrete joints", Structure Engineering and Mechanics, 7(4), pp. 413432 (1999).

14. Elmorsi, M., Kianoush, M.R. and Tso, W.K. "Modeling bond-slip deformations in reinforced concrete beam-column joints", Canadian Journal of Civil Engineering, 27, pp. 490-505 (2000).

15. Youssef, M. and Ghobarah, A. "Modelling of RC beam-column joints and structural walls", Journal of Earthquake Engineering, 5(1), pp. 93-111 (2001).

16. Spacone, E., Filippou, F.C. and Taucer, F.F. "Fibre beam-column model for non-linear analysis of $\mathrm{R} / \mathrm{C}$ frames: Part I. formulation", Earthq. Eng. Struct. Dyn., 25(7), pp. 711-725 (1996).

17. Sharma, A., Eligehausen, R. and Reddy, G.R. "A new model to simulate joint shear behavior of poorly detailed beam-column connections in RC structures under seismic loads, Part I: Exterior joints", Engineering Structures, 33, pp. 1034-1051 (2011).

18. Lowes, L.N. and Altoontash, A. "Modeling reinforcedconcrete beam-column joints subjected to cyclic loading", Journal of Structural Engineering, ASCE, 129(12) pp. 1686-1697 (2003).

19. Altoontash, A. "Simulation and damage models for performance assessment of reinforced concrete beamcolumn joints", Ph.D. Dissertation, Stanford (CA): Department of Civil and Environment Engineering. Stanford University (2004).

20. American Concrete Institute (ACI-318) Building Code Requirements for Reinforced Concrete, Farmington Hills, MI (2011).

21. Pampanin, S., Calvi, G.M. and Moratti, M. "Seismic behaviour of RC beam-column joints designed for gravity loads", 12th ECEE, London, paper no. 726 (2002).
22. Dassault Systems Simulia Corp, Abaqus Analysis User's Manual, Version 6.11-1 (2011).

23. Lee, J. and Fenvas, G.L. "Plastic-damaged model for cyclic loading of concrete structures", Journal of Engineering Mechanics, 124, pp. 892-900 (1998).

24. Kwon, M.H., Shing, P.B., Mallare, C. and Restrepo, J. "Seismic resistance of RC bent caps in elevated mass transit structures", Earthquake Spectra, 27(1), pp. 6788 (2011).

25. Kim, J.S., Kwon, M.H., Jung, W.Y. and Limkatanyu, $\mathrm{S}$. "Seismic performance evaluation of RC columns reinforced by GFRP composite sheets with clip connectors", Construction and Building Materials, 43, pp. 563-574 (2013).

\section{Biographies}

WooYoung Jung is a Professor of Structural Engineering in the Department of Civil Engineering at Gangneung-Wonju National University, Gangneung, South Korea. His research interests are seismic rehabilitation for RC and steel structures by using Fiber Reinforcing Polymer (FRP), earthquake resisting design and seismic fragility assessment, and experimental research on existing structures under severe loads. He has conducted many research projects with government and industry and is a member of Korean Society of Civil Engineers.

Jinsup Kim is an Assistant Professor of Structural Engineering in the Department of Civil Engineering at Gyeongsang National University, Jinju, South Korea. His research interests include the seismic analysis, design, and retrofitting of RC and steel structures using Fiber-Reinforced Polymer (FRP), Ultra-High Performance Fiber Reinforced Concrete (UHPFRC), earthquake engineering, and FE analysis.

Minho Kwon is a Professor of Structural Engineering in the Department of Civil Engineering at Gyeongsang National University, Jinju, South Korea. His main research interests are finite element modeling for RC and steel structures, aircraft crash analysis, earthquake resisting design, constitutive modeling, and experiment of RC structures under severe loads. He has conducted many research projects with government and industry and is a member of American Society of Civil Engineers and Korean Society of Civil Engineers. 